\title{
Article \\ Energy Analysis of an Industrial Nozzle with Variable Outlet Conditions during Compressible and Transient Airflow
}

\author{
Krzysztof J. Wołosz (D)
}

Faculty of Civil Engineering, Mechanics and Petrochemistry, Warsaw University of Technology, Łukasiewicza 17, 09-400 Płock, Poland; Krzysztof.Wolosz@pw.edu.pl

\begin{abstract}
The nozzle which is applied in industrial pneumatic pulsators is studied. It is a part of the system for unclogging the drains and outlets of silos and hoppers for loose materials. The nozzle is required to achieve the lowest level of energy losses while directing the airflow, which impacts the loose material bed. The energy rate transferred into the bed depends on the temperature and pressure differences between the inlet and outlet of the nozzle. In this study, the available energy is determined assuming compressible and transient airflow through the nozzle, which is a part of the industrial pneumatic pulsator. Numerical simulations are performed using the OpenFOAM CFD toolbox. Energy analysis is carried out by using Reynolds Transport Theorem for specific energy for the variable temperature inside the silo on the basis of CFD results. In fact, the air parameters at the outlet of the nozzle are the ones inside the silo. The study showed that the design of the nozzle is not very sufficient from an energetic point of view.
\end{abstract}

Keywords: computational fluid dynamics; transient compressible flow; pneumatic pulsator

\section{Introduction}

The efficient use of energy remains at the centre of interest at some time. While the word "energy" is commonly and intuitively recognised, this concept has not yet received a clear and precise definition. Leibnitz and Descartes already made attempts to define energy as a "quantity of motion" [1]. Another definition is "the first integral of the equations of a physical system motion [2]. Most often, however, the authors give up defining the concept of energy by presenting only its forms [3,4], or by associating the change in the quality of energy with the concept of entropy [5]. Energy is assumed to be a scalar quantity characterising the ability to perform work by a physical system in most encountered cases. However, energy changes its form and quality while performing this work, which does not allow it to be done. Prominent examples are friction and heat losses during thermodynamic gas conversions. The concept of exergy has been defined for these reasons: the amount of energy that can be converted into work. Exergy does not consider energy losses, but it does environmental conditions because no physical system is fully insulated.

This article presents a study of the problem of energy and exergy on the example of a system used in industry, particularly one of its components, the nozzle. It is a broader version of the SDEWES Conference paper presented in Dubrovnik in October 2021.

In industries that use loose materials, there are devices for destroying unfavourable structures of these materials. They are mainly used in the pharmaceutical and heavy industries. The structures are related to the forces specific to loose materials, i.e., cohesion. When the cohesion forces are larger than the gravity, the loose material conglomerates into larger structures. It may also cause the clogging of the silo drains in which the material is stored. The systems preventing those situations are called pneumatic pulsators, air cannons or air blasters. The name comes from the term "pneumatic impact" utilised in these systems. The pneumatic impact is used in systems that require a dynamic, high force impact on distributed objects. Another application can also be a rapid gas exchange in closed areas,

Copyright: (c) 2022 by the author Licensee MDPI, Basel, Switzerland. This article is an open access article distributed under the terms and conditions of the Creative Commons Attribution (CC BY) license (https:// creativecommons.org/licenses/by/ $4.0 /)$. 
e.g., ventilation and firefighting. The pneumatic impact is a highly transient phenomenon that does not allow a simplification of computational models to analyse such flows. For this reason, these analyses must take into account transient and compressible flow models.

The last component of the system mentioned above is a nozzle. This element is designed to distribute the pneumatic impact energy to the loose material area where unfavourable structures are present. An additional task of this element is to protect the entire pneumatic pulsator system from heat from inside the silo. This heat can be generated, for example, by storing hot loose materials such as clinker. It also should be noted that the term "nozzle" is a commonly used term, while the flow characteristic inside this device varies during the working cycle. It means that it can work as a confuser (nozzle) and as a diffuser as well. The change in operating characteristics is due to the highly transient working cycle and the gas pressure and momentum changes.

The key research issue is the quality (exergy) and quantity of energy utilisation in the nozzle. Nozzles are commonly investigated regarding flow phenomena by using numerical and experimental methods as well. The authors focus on heat transfer efficiency [6] or on entropy generation $[7,8]$. There are also studies of the specific applications of nozzles in turbines [9], and the phenomena of sound wave generation and their impact on entropy [10]. An essential part of nozzle research is the focus on the automotive industry. Studies in this area focus primarily on droplet size [11]. Besides the nozzle, the ejectors and jets are also in great interest of researchers, particularly in increasing efficiency [6]. A very in-depth analysis of streamer operation can be found in the work [12] due to the detailed analysis of turbulence models. From the CFD point of view, it is essential to evaluate how the numerical models agree with the analytical ones, as presented in [13]. The authors focused on the effect of entropy on acoustic phenomena and made a valuable comparison between one- and two-dimensional computational models of jets.

A valuable work due to the possibility of carrying out verification of numerical calculations in terms of flow phenomena is reported in [14]. But also some references have played a significant role for the verification of solver [15,16] and numerical models [17]. It is crucial to select an appropriate computational mesh for proper calculation procedure. It turns out that increasing the accuracy of the computational grid does not necessarily translate into increasing the reliability of the calculation, as shown in [18]. These studies have impacted the present work due to possible computational uncertainties.

In the whole spectrum of flow studies on nozzles, there is a significant lack of investigation on non-axisymmetric nozzle shape considering transient flow. The research presented in this paper fills the gap in this area, especially when considering circular flows inside the nozzle.

Books referencing energy, exergy and entropy are an essential part of the literature review with energy efficiency taken into account $[3,19,20]$. For the issues of gas energy utilisation and exergy loss generation, the author focuses on identifying local sources of entropy [21]. This work is based on the models reported in [20] and deals with aircraft engines. The computational models are two-dimensional and steady-state. A very interesting analysis involving the second law of thermodynamics is found in the work [7]. The authors attempted to optimise the shape of the confuser and diffuser (separately) to minimise local entropy sources. An interesting approach can be found in the reference [22], where an analytical approach to entropy calculations in nozzles with non-uniform cross-section is presented. However, this approach is inapplicable from a practical point of view due to the assumed uniformly defined curvatures (concave or convex). The above works related to energy efficiency do not present a universal model to analyse the elements of transient systems. A study of a pneumatic pulsator (air cannon) system on a laboratory scale is presented in the work [23]. This research concerned the experimental confirmation of analytical models to determine the release velocity from the pulsator. This research, which is vital given the subject of this article, is of a small scale and with little applicability on an industrial scale, which has been confirmed in the paper [24]. 
Preliminary studies of industrial nozzles have already been carried out using energy and flow analysis [25,26]. The main focus of this work has been on the development of methods to determine the magnitude of gas energy and the determination of important flow parameters affecting exergy and exergy losses.

The determination of gas energy and exergy is not commonly found in the literature. The situation is especially actual for compressible and transient flows. Additionally, the present study is a niche due to industrial applications. The literature survey shows a lack of analytical models for the analysis of the nozzle under study. In particular, energy analysis is not subjected to such studies. In conclusion, the work presented in this paper fills the gap in the context of transient, compressible studies in channels with variable non-axisymmetric cross-sections.

\section{Numerical Model}

The main tool used for the study was the finite volume method, and the simulations were performed by using the OpenFOAM ${ }^{\circledR}$ toolbox [27]. The computational model used in the simulations is based on the geometry of an actual functioning nozzle in heavy industry. Furthermore, the physical model and the phenomena involved are derived from the working cycle of the pneumatic pulsator system. For this reason, the principle of operation is briefly outlined below. The system visualisation is shown in Figure 1 together with an example of the location on a silo.

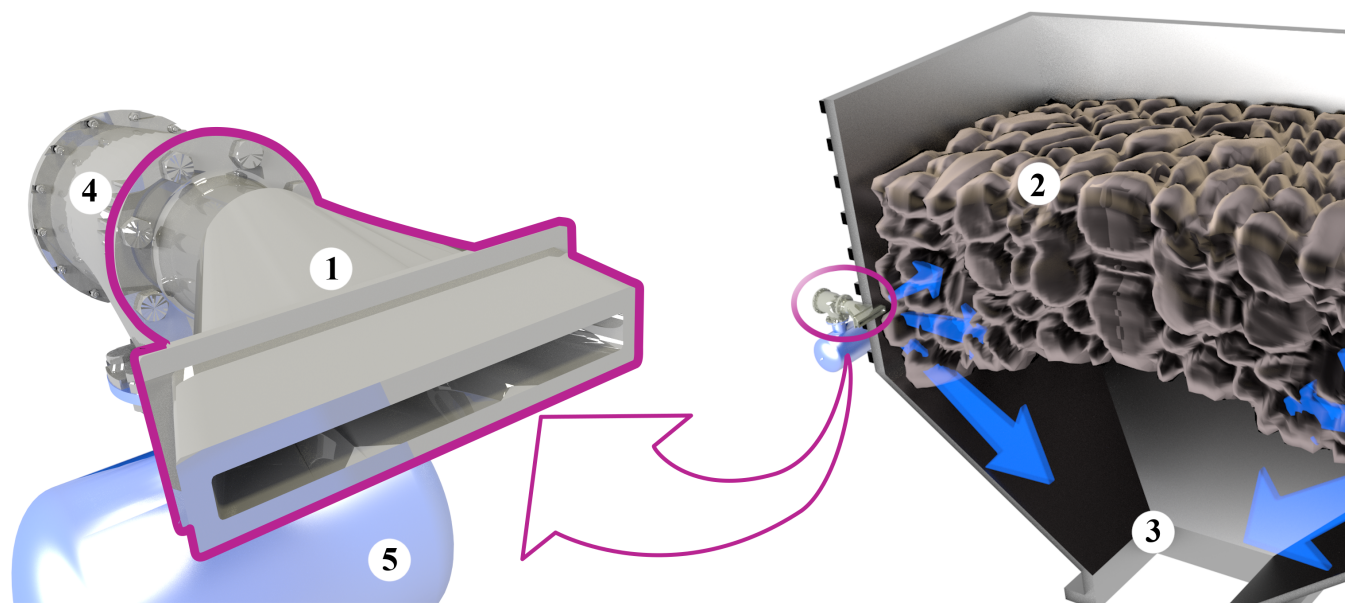

Figure 1. Visualization of the pneumatic pulsator system, and their location on silo walls: 1—nozzle (outlined investigated object); 2-loose material; 3-silo (cross-section); 4-head; 5-pressure accumulator. Blue arrows show possible direction of impact.

The source of the pneumatic impact is the compressed air contained in the pressure accumulator 5 . The system working cycle begins with activating the quick-acting valve located in the head 4 . Then, the air is guided through the nozzle 1 to the silo 3 . The momentum of the expanded air creates the pneumatic impact that acts on the loose material 2. The working cycle of the pneumatic pulsator system stops when the pressure between the pressure accumulator and silo (environment) becomes equal.

The system visualisation is shown in Figure 1 together with an example of the location on a silo.

The numerical mesh covers the area inside the nozzle to obtain the flow parameters. A visualisation of the nozzle cross-section and the considered computational area is shown in Figure 2. The nozzle is made of cast iron or cast steel and equipped with baffles to increase the heat capacity of the nozzle. The influence of these baffles on the efficiency of the nozzle is also of interest to the author. The nominal diameter of the nozzle inlet is $150 \mathrm{~mm}$. The other main dimensions of the nozzle are length in the flow direction $320 \mathrm{~mm}$, width at the outlet $487 \mathrm{~mm}$ and height $325 \mathrm{~mm}$. The cross-sectional area of the nozzle is changing: at the inlet $-102.3 \mathrm{~cm}^{2}$ and at the outlet $-77.5 \mathrm{~cm}^{2}$. 
The calculation area was covered with a hexahedral numerical mesh of 1,200,000 cells. The computational cost reduction was possible by taking advantage of the symmetrical design. It reduced the number of calculation cells by two while maintaining the same calculation accuracy. Detailed computational models together with the methodology for calculating the computational inaccuracy are given in the following Sections 2.1-2.3.

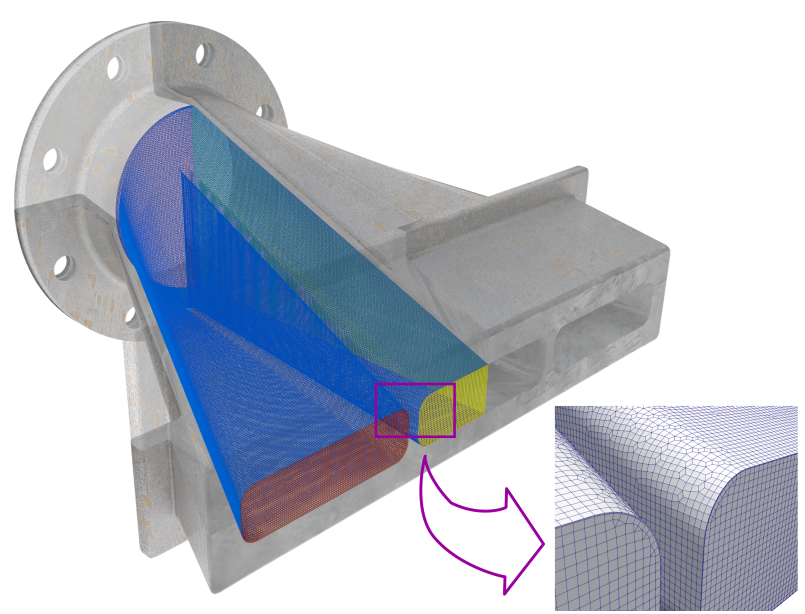

Figure 2. Visualization of investigated nozzle with numerical mesh applied.

\subsection{Governing Equations}

To specify the flow parameters in the numerical simulation, the mesh shown in Figure 2 is used. The analytical solution of the mass, momentum and energy balances for the entire considered area is not possible [28]. It is, however, possible to determine these balances for a single mesh cell with simple geometry. The following equations are mathematical expressions of the corresponding laws for a single mesh cell.

\subsubsection{Mass Balance}

Given a single cell of the calculation area, the sum of the incoming and outgoing fluxes must be zero as long as no mass is created or destroyed during the motion. In the case under consideration, neither chemical nor nuclear reactions occur; hence the sum of the inlet and outlet mass fluxes is zero. Due to the transient and compressible nature, the mass balance must also consider the change in density with time and the fact that density affects the mass flux. Therefore, the mass balance in conservative form is as follows:

$$
\frac{\partial \rho}{\partial t}+\nabla \cdot(\rho \vec{u})=0
$$

where $\rho$ denotes density, $t$ time, and $\vec{u}$ velocity vector.

\subsubsection{Momentum Balance}

Forces act on a single fluid element in a single cell of the computational mesh. The forces cause stresses, which in turn induce strains on that element. The determination of stresses and strains is made possible through momentum balance. The balance sums the dynamic and pressure forces of the fluid, minus the wall reactions and gravity. For the local conditions, for a considered flow, this balance is of the following form:

$$
\frac{\partial \rho \vec{u}}{\partial t}+\nabla \cdot(\rho \vec{u} \vec{u})-\nabla \cdot \mu \nabla \vec{u}=-\nabla p,
$$

where $\mu$ is dynamic viscosity and $p$ is pressure.

The considered medium is a real gas in which viscosity affects the momentum balance equation. Viscosity is a physical quantity that strongly depends on temperature. There- 
fore, the mathematical model should include a term describing the viscosity change with temperature. Sutherland's law represents this change as follows:

$$
\mu=A_{s} \frac{\sqrt{T}}{1+T_{s} / T},
$$

where Sutherland coefficient $A_{s}=1.53 \times 10^{-6}$, and Sutherland temperature $T_{s}=127.67$.

\subsubsection{Energy Balance}

Energy must also be balanced in conjunction with mass and momentum. In the computational cell, the energy flux entering the cell is enlarged by the thermal (heat) and mechanical energy flux. The sum of these energy fluxes is equal to the residual energy flux exiting the cell. A mathematical expression of this is represented in a conservative form in the energy balance as follows:

$$
\frac{\partial \rho e}{\partial t}+\nabla \cdot(\rho \vec{u} e)-\nabla \cdot\left(\frac{\lambda}{c_{v}}\right) \nabla e=p \nabla \cdot \vec{u},
$$

in which $e$ denotes internal energy, $\lambda$-thermal conductivity of air, and $c_{v}$ is specific heat at constant volume. Internal energy $e$ is calculated according the following formula:

$$
e=c_{v} T,
$$

where $T$ denotes temperature.

The equations presented above must be complemented by a heat conduction equation that relates the heat flux to the temperature gradient:

$$
\vec{q}=-\lambda \nabla T,
$$

in which $\vec{q}$ denotes heat flux.

Air is assumed to be a thermodynamically ideal gas according to the equation:

$$
R=c_{p}-c_{v}=\frac{p}{\rho T}=287 \frac{\mathrm{J}}{\mathrm{kg} \cdot \mathrm{K}^{\prime}}
$$

in which $R$ denotes gas constant and $c_{p}$ specific heat at constant pressure.

The system of Equations (1)-(7) was solved numerically with the finite volume method. The equations were discretised using an appropriate discretisation scheme. For the spatial discretisation, a linear Gaussian scheme was used, which is second order accurate. Since transient airflow is considered, a second order accurate Crank-Nicolson scheme was used for the temporal discretisation.

\subsection{Turbulence Model}

The previous Section 2.1 presented equations that must be solved by numerical methods. An additional complication is the fact that the above equations are valid for laminar flows or for flows for which the length and time scale according to Kolmogorov [29] are preserved. For the considered case, more than 80,000,000,000 numerical cells would be necessary to follow the Kolmogorov scale. This number of elements is computationally expensive. For this reason, turbulence models are used for averaging. It gives relatively reliable calculations in a reasonable time.

The turbulence models can be divided into two main groups: LES and RANS. A detailed description of each group of turbulence simulation models is beyond the scope of this paper. Therefore, with the help of the literature survey, a standard $k-\varepsilon$ [30] model was assumed for two main reasons: the presented investigations are focused on the flow parameters rather than an influence of a flow on walls or objects, and it is well-validated in cases where parameters of free-stream are most important in investigation [28,31]. The $k-\varepsilon$ 
turbulence model gives two additional governing equations to the model. These equations describe kinetic energy of turbulence $(k)$ and dissipation rate of this energy $(\varepsilon)$ and are as follows:

$$
\begin{gathered}
\frac{\partial}{\partial t}(\rho k)+\nabla \cdot(\rho k \vec{u})=\nabla \cdot\left[\left(\mu+\frac{\mu_{t}}{\sigma_{k}}\right) \nabla k\right]+P_{k}-\rho \varepsilon-Y_{M}+S_{k}, \\
\frac{\partial}{\partial t}(\rho \varepsilon)+\nabla \cdot(\rho \varepsilon \vec{u})=\nabla \cdot\left[\left(\mu+\frac{\mu_{t}}{\sigma_{\varepsilon}}\right) \nabla \varepsilon\right]+C_{1 \varepsilon} \frac{\varepsilon}{k} P_{k}-C_{2 \varepsilon} \rho \frac{\varepsilon^{2}}{k}+S_{\varepsilon},
\end{gathered}
$$

in which $C_{1 \varepsilon}=1.44, C_{2 \varepsilon}=1.92, C_{\mu}=0.09, \sigma_{\varepsilon}=1.3, \sigma_{k}=1.0$ are mathematical model constants and they are taken from experimental validation of this model [31]. Turbulent viscosity $\mu_{t}$ is calculated according to the following relation:

$$
\mu_{t}=\rho C_{\mu} \frac{k^{2}}{\varepsilon} .
$$

Equations (8)-(10) consist of several turbulence parameters such as:

- the generation of turbulence kinetic energy due to the mean velocity gradients:

$$
P_{k}=-\rho \overrightarrow{\vec{u}^{\prime}} \overrightarrow{u^{\prime}} \nabla \vec{u}
$$

where $\overrightarrow{u^{\prime}}$ is a vector of velocity fluctuation and the term $\overrightarrow{u^{\prime}} \overrightarrow{u^{\prime}}$ delivers mean value of the tensor product,

- $\quad$ the moduli of the mean rate-of-strain tensor $S_{k}$ and $S_{\varepsilon}$ :

$$
S \equiv \sqrt{2(\vec{S}: \vec{S})}
$$

in which the term $\vec{S}: \vec{S}$ gives the scalar product of the rate-of-strain tensor,

- the viscous destruction:

$$
Y_{M}=2 v \overline{\left(\nabla^{2} \overrightarrow{u^{\prime}}\right)^{2}}
$$

where $v$ denotes kinematic viscosity.

\subsection{Boundary Conditions}

Boundary conditions are indispensable for solutions to differential equations, both linear and non-linear. The calculation of transient conditions additionally requires initial conditions. Hence, boundary and initial conditions must be stated correctly in order to numerically solve the system of equations presented in Sections 2.1 and 2.2. They are the output of both the geometric model and the physical model. Appropriate boundary and initial conditions define the nature of the phenomena and flow characteristics in the nozzle. Nozzles are usually used under normal conditions. For this reason, the assumed initial conditions are close to normal technical conditions. The conditions described in detail below result from the assumptions made and the physical model.

Geometrical symmetry was taken advantage of by using symmetry plane boundary condition. Hence, the mesh size was reduced by two. Outlets of nozzles had initial temperature set to $300 \mathrm{~K}$. Velocity and temperature gradients were zero according to Neumann-type. Walls of the nozzles are made of cast iron, and therefore, they were assumed as impermeable. The entire transient process lasted very short time period as it will be shown in subsequent Section 4 . Hence, the walls of the nozzles were assumed adiabatic which was crucial due to thermodynamic issues.

The driving force of the process is the pressure difference on both sides of the nozzles. The value of the pressure at the inlet is taken from a previously published study on the evacuation of a pressure accumulator in order to bring the case as close as possible to the actual operating conditions of a pneumatic pulsator system. According to the shock wave 
theory, the value of the boundary (patch) pressure at the inlet is determined from the total pressure, as follows:

$$
p_{p}=\frac{p_{0}}{\left(1+\frac{\gamma-1}{2 \gamma} \psi\|\vec{u}\|^{2}\right)^{\gamma /(\gamma-1)}}
$$

where $p_{p}$ denotes boundary (patch) pressure, $p_{0}$-total pressure, and $\gamma=c_{p} / c_{v}$ is adiabatic index. The term $\psi=1 /(R T)$ denotes compressibility. Values of inlet pressure as well as total pressure time distribution is graphically shown in Figure 3.

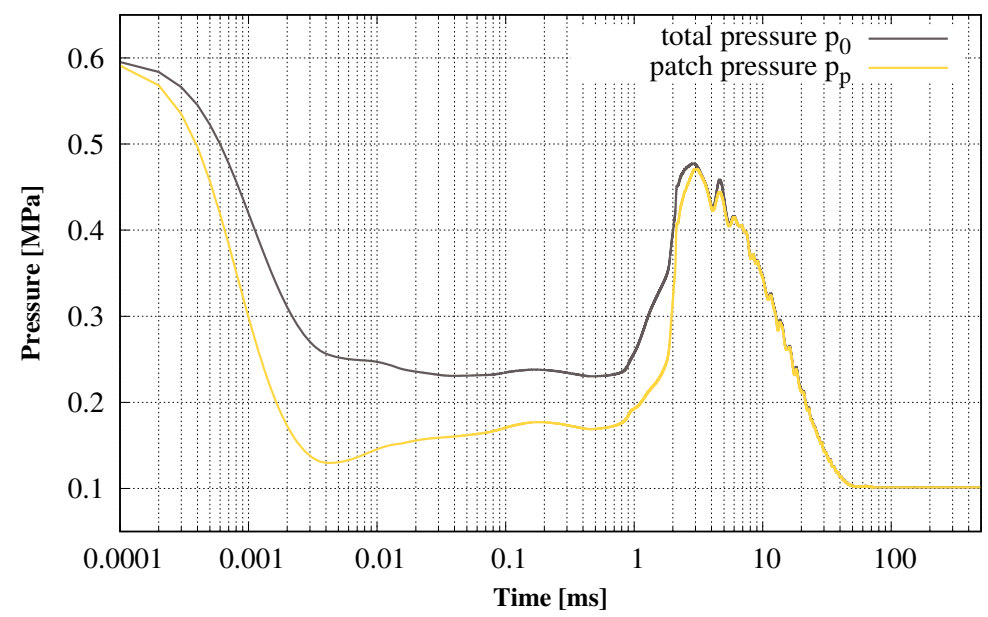

Figure 3. Time distribution of inlet static pressure for both investigated cases on the background of the total pressure. Reproduced from [32].

Temperature is also influenced by velocity similarly to the case of pressure. Therefore, inlet temperature was calculated according to the following formula:

$$
T_{p}=\frac{T_{0}}{1+\frac{\gamma-1}{2 \gamma} \psi\|\vec{u}\|^{2}}
$$

where $T_{0}=300 \mathrm{~K}$ denotes total temperature and the values of $T_{p}$ are shown in graph in Figure 4 .

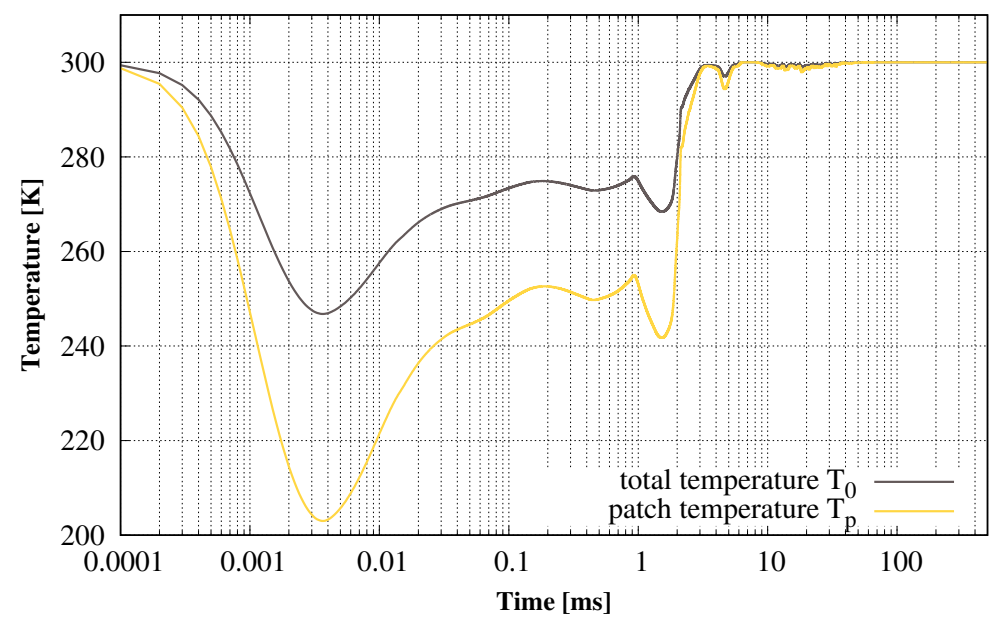

Figure 4. Time distribution of inlet temperature for both investigated cases.

It is also important to properly state outlet condition for pressure. For example, if one chooses Dirichlet or Neumann type boundary condition, shock reflection can be expected. Therefore, Robin-type boundary condition [33] was applied for outlet pressure. OpenFOAM 
toolbox employs this type in wave transmissive condition and outlet pressure was calculated according to the following formula:

$$
\frac{\partial p_{\text {out }}}{\partial t}+\vec{u}\left(\vec{n} \cdot \nabla p_{\text {out }}\right)=\frac{\vec{u}}{l_{\infty}}\left(p_{\infty}-p_{\text {out }}\right) .
$$

Outlet pressure $p_{\text {out }}$ was calculated with assumption of its far field value $p_{\infty}$ which was namely environmental one. The far field pressure was located from outlet surface, described by normal vector $\vec{n}$, by distance $l_{\infty}=1 \mathrm{~m}$ and it was constant and equaled $p_{\infty}=101,325.0 \mathrm{~Pa}$.

Wave transmissive boundary condition minimises number of cells in numerical mesh and the values of source terms are "transferred" from the outlet to the environment.

Boundary conditions for turbulent energy $k$ and turbulent dissipation rate $\varepsilon$ were the Neumann type, i.e., $\vec{n} \cdot \nabla \phi=0$. The initial values of these terms were taken from out previous work [24]: $k=11.38 \mathrm{~J} / \mathrm{kg}, \varepsilon=11,855.0 \mathrm{~W} / \mathrm{kg}$.

As mentioned, there was a symmetrical flow assumed in both models. Thus, there was only one half of the nozzle analysed with the symmetry plane boundary condition applied. This condition equalises the gradients of scalar quantities to zero.

\subsection{Solver Validation E Error Estimation}

The essential parts of a numerical simulation are verifying the numerical model and validating the solver. Solver validation shows whether the governing equations describe the investigated phenomena correctly or not. Model verification shows whether the governing equations are solved correctly. The benchmark model was built in OpenFOAM based on the experimental setup described in [34], and the results were compared for solver validation. In the present work, compressible airflow was used, so the comparison of shockwave contours answers the above question. The shockwave contours obtained in the author's comparison case are shown in Figure 5, while the experimental results are presented in Figure 16 of reference [34]. Shockwaves cause an increase in air density and can therefore be visualised using the schlieren technique. This technique uses light diffraction when density gradients are present. A similar technique is used in numerical simulations and is called pseudo-schlieren. In numerical simulations, density gradient results are used to compare numerical results with experiments. The distribution of shockwaves was similar in the compared cases. In the reference [34] the density gradient scale is not given, which may imply differences in the results. The position of the shockwave can serve as a quantitative comparison.

Another important issue during numerical simulation is model verification. There are several ways to perform it, but the most common is to compare it with experimental results. Currently, it is not technically possible to obtain experimental data from industrial facilities where pneumatic pulsators are used. Therefore, the verification of the model was carried out by satisfying convergence criteria and estimating numerical errors.

The numerical simulation, especially considering transient phenomena, must satisfy the Courant-Friedrich-Lewy condition [35]. It is crucial for the stability of the simulation that the Courant number does not exceed $C_{\max }=1$. This condition was fulfilled, as can be observed in Figure 6.

Error estimation has been carried out by using the procedure proposed in [36] and described in detail in [37]. In this procedure, the Grid Convergence Index (GCI) for coarse and fine mesh need to be calculated. Therefore, additional simulations must be carried out. In the present study, GCI for coarse mesh was $G C I_{\mathcal{c}}=0.0101$ and for fine mesh $G C I_{f}=0.0061$. That made it possible to qualify the model correctness beyond the discretization error. If the condition $G C I_{c}>G C I_{f}$ was fulfilled, the results for the fine mesh were more reliable, confirming the model correctness. 


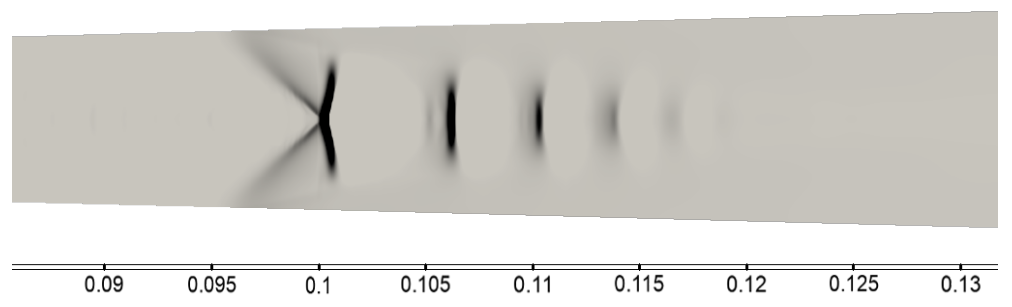

Figure 5. Results obtained by the author during current study for a qualitative comparison with experimental taken from [34].

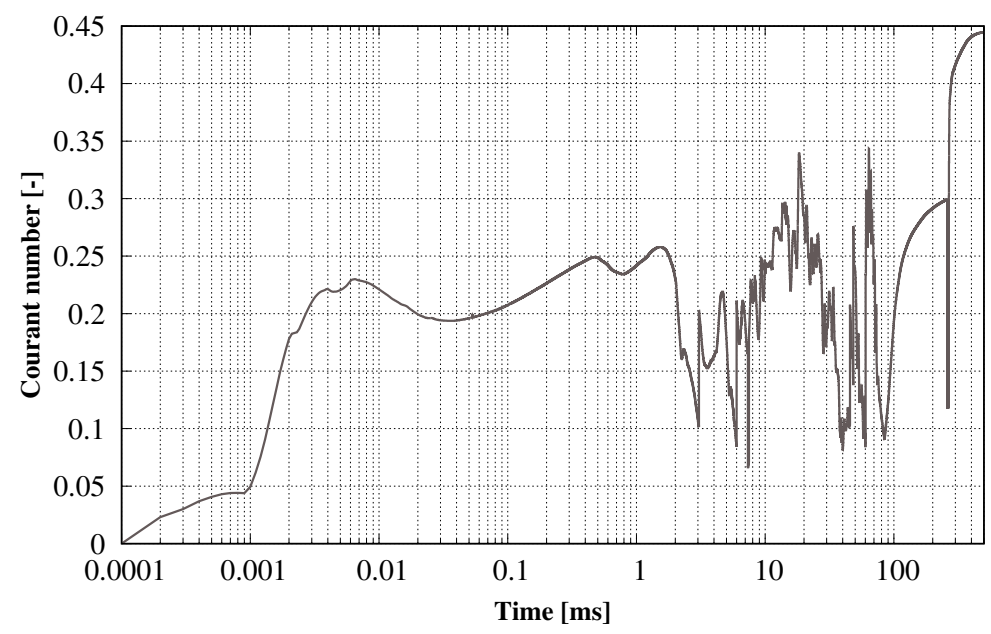

Figure 6. Courant-Friedrichs-Levy convergence condition plot during simulation time.

\section{Exergy Destruction}

The energy carried by air flowing through the nozzle cannot disappear or arise from nothing. The exergy, which by definition is an energy quality, can be destroyed in part or in full. Given the assumed boundary conditions presented in Section 2.3, the flow is transient and compressible. All flow parameters that impact the amount of energy and exergy will be subject to time variation. Compressibility causes the accumulation of energy through compression at a given moment in time. Then, the energy is released from the nozzle through decompression. This implies a change in energy at the inlet and outlet at a given moment in time. The model for estimating energy and exergy quantities presented below will be considered for a single time step of the numerical simulations being carried out. Therefore, it is convenient to use energy and exergy rates in the analysis to illustrate their changes over time. In order to carry out the energy balance and determine the outlet exergy of the system, the energy and exergy rates must be integrated for all available time steps of the entire working cycle of the pulsator nozzle. The numerical simulation results are used to determine the energy and exergy at the inlet and outlet of the nozzle. The balance shield, in this case, corresponds to the boundary conditions used in the numerical analysis.

\subsection{Energy}

The energy flux entering the system and the energy changes in the control volume equal the amount of energy exiting the considered system. According to conservation law, energy cannot be created or destroyed. However, it can change its form. The change in the energy flux in the control volume is conveniently represented in integral form. At a given moment in time and given control volume, the total energy flux is a change of energy, and the sum of the energy fluxes delivered to and received from that volume. 
The mathematical expression is the First Law of Thermodynamics (FLT) for thermodynamic systems, which is the Reynolds Transport Theorem for specific energy [38]:

$$
\dot{E}=\frac{\partial}{\partial t} \int_{V} \rho\left(e+\frac{1}{2} \vec{u} \cdot \vec{u}\right) \mathrm{d} V+\oint_{A} \rho\left(e+\frac{1}{2} \vec{u} \cdot \vec{u}\right) \vec{u} \cdot \vec{n} \mathrm{~d} A,
$$

where $\dot{E}$ denotes energy rate, $V$ is control volume, $\vec{n}$ is normal vector to boundary area $A$. The last term in this equation $\vec{u} \cdot \vec{n} \mathrm{~d} A$ is volumetric flux through infinitesimal boundary area $\mathrm{d} A$. The first integral in Equation (17) is of no value if there is neither chemical nor nuclear reaction, i.e., there are no internal heat sources. Airflow through the nozzle proceeded very fast; therefore, adiabatic gas conversion can be considered. With these assumptions, FLT looks as follows:

$$
\dot{E}=\oint_{A} \rho\left(e+\frac{1}{2} \vec{u} \cdot \vec{u}\right) \vec{u} \cdot \vec{n} \mathrm{~d} A .
$$

By substituting:

$$
\mathrm{d} \dot{m}=\rho \vec{u} \cdot \vec{n} \mathrm{~d} A,
$$

and integrating the surface integral Equation (18) one can obtain energy rate dependent from mass flux which is more convenient for the present study.

The boundary area $A$ is limited to inlets and outlets because of the impermeability of nozzle walls. The values have been area-weighted averaged to predict total energy rates, and the FLT is:

$$
\dot{E}=\dot{m}\left(\bar{e}+\frac{1}{2} \overline{\vec{u} \cdot \vec{u}}\right),
$$

where $\dot{m}$ is mass flux of the gas.

\subsection{Exergy}

Exergy, as mentioned above, quantitatively is the greatest energy that can be converted into work. The considered system, i.e., the nozzle, is an open system in which no work is performed. The gas will perform work after leaving the system only, i.e., on the loose material. The absence of work done by the gas is a sine qua non for the exergetic analysis of the transient state [39]. This study aims to determine the amount of exergy destruction lost through the gas flow through the nozzle alone. Including all inlet and outlet streams in a comprehensive analysis makes it possible to determine the degree to which the system destroys exergy by determining the exergy flux. The exergy destroyed is proportional to the entropy generated. Exergy is always destroyed, partially or totally: this is a statement in the second law of thermodynamics. The exergy destroyed or entropy generated is responsible for the nozzle thermodynamic efficiency being less than theoretical [40].

In an open system, the exergy flux of the flowing mass is the sum of the nonflow exergy and the exergy associated with the change in gas operating parameters. Alternatively, the exergy flux can be divided into physical, chemical, kinetic and potential exergy as reported in [41]. Airflow through the nozzle encloses neither chemical nor nuclear reaction. The nozzle is fixed on the wall of the silo. Therefore, the potential and kinetic exergy of the system is invariant. Only the physical exergy needs to be taken into account and is influenced by pressure and temperature. The physical exergy rate in $[\mathrm{W}]$ equals:

$$
\dot{E x}=\dot{m}\left[\left(h-h_{0}\right)-T_{0}\left(s-s_{0}\right)\right],
$$


where $\dot{E} x$ denotes exergy rate, $h$ is specific enthalpy, $s$ is specific entropy, and index 0 points environmental values. Physical exergy can be split apart at temperature dependent and pressure dependent ones:

$$
\begin{aligned}
& \dot{E x}=\dot{E} x_{T}+\dot{E} x_{p} \\
& \dot{E} x_{T}=\dot{m}\left[\left(h-h_{0}\right)-T_{0}\left(s-s_{0}\right)\right]_{p=\text { const }} \mid T_{T_{0}}^{T} \\
& \dot{E} x_{p}=\left.\dot{m}\left[\left(h-h_{0}\right)-T_{0}\left(s-s_{0}\right)\right]_{T=\text { const }}\right|_{p_{0}} .
\end{aligned}
$$

Combining Equation (22) with equation of state Equation (7), the physical exergy is as follows:

$$
\begin{aligned}
& \dot{E x_{T}}=\dot{m} c_{p}\left(T-T_{0}-T_{0} \ln \frac{T}{T_{0}}\right) \\
& \dot{E} x_{p}=\dot{m} R T_{0} \ln \frac{p}{p_{0}} \\
& \dot{E x}=\dot{m} c_{p}\left(T-T_{0}-T_{0} \ln \frac{T}{T_{0}}\right)+\dot{m} R T_{0} \ln \frac{p}{p_{0}} .
\end{aligned}
$$

Total physical exergy is calculated according to aforementioned equation outlet crosssection of the nozzle. Quantities included in Equation (23) are area averaged in space to conveniently proceed exergy analysis.

\section{Results \& Discussion}

The results of the study are based on the results of numerical simulations. Since the numerical calculations were considered transient, most of the analysis will be presented in graphs showing the variation in time of the parameters considered. The results will be divided into two main categories: flow phenomena and energy analysis. Section 4.1 presents the results of the calculations of the flow parameters that are crucial for the amount of energy transferred to the loose material. Due to channels with a non-uniform crosssectional area, the results will also be presented to show how the considered quantities change depending on the considered outlet channel. It is essential due to the uniform energy transfer to the loose material. Figure 7 shows the Cartesian axes directions superimposed on the nozzle cross-section and the names distinguishing the nozzle channels.

The graphs presented in this section are shown in the logarithmic $x$-axis due to the very intense gas flow in the first milliseconds of the process.

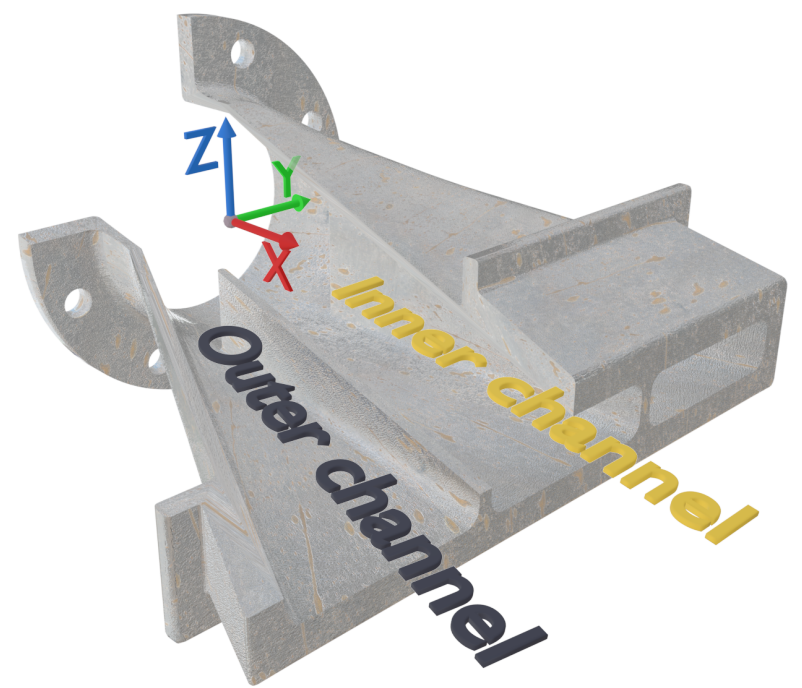

Figure 7. Nomenclature for results and axes location. 


\subsection{Flow Parameters Results}

The first parameter analysed is the velocity. As velocity is squared in Equation (20), it can have a decisive influence on the amount of energy transferred from the nozzle. Figure 8 shows the variation of the average velocity value for the inlet and outlet of the nozzle. The highest average velocity of the gas is reached at the inlet and is $320 \mathrm{~m} / \mathrm{s}$.

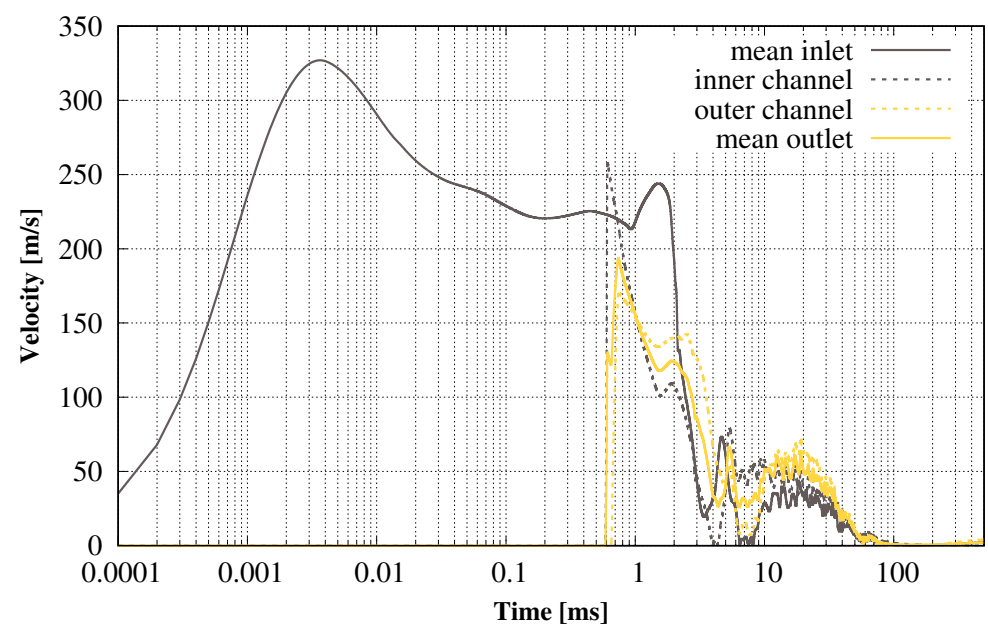

Figure 8. Area-averaged velocity magnitude considering inlet,outlet and each outlet channel of the nozzle.

Due to the transfer of gas energy out of the nozzle, it is essential to analyse the exit velocity from the nozzle. Figure 9 shows the velocity distribution depending on the direction of action. The dominant direction of action is, for obvious reasons, the longitudinal axis of the nozzle. Interestingly, there is a change in the dominant channel in terms of velocity value during the flow. There is a very rapid velocity decrease in the inner channel, from a maximum value of about $250 \mathrm{~m} / \mathrm{s}$ to 0 after about $4.5 \mathrm{~ms}$. At the same time, there is no such rapid decrease of velocity in the outer channels. This results in a higher velocity value in the outer channels after $1 \mathrm{~ms}$. A significant difference between values can be observed considering velocity in the y-direction. It comes directly from the nozzle design. So, jet dispersion fulfils its purpose. After about $5 \mathrm{~ms}$ from the start of the simulation, significant velocity fluctuations can be seen, which disappear at about $100 \mathrm{~ms}$ from the start.

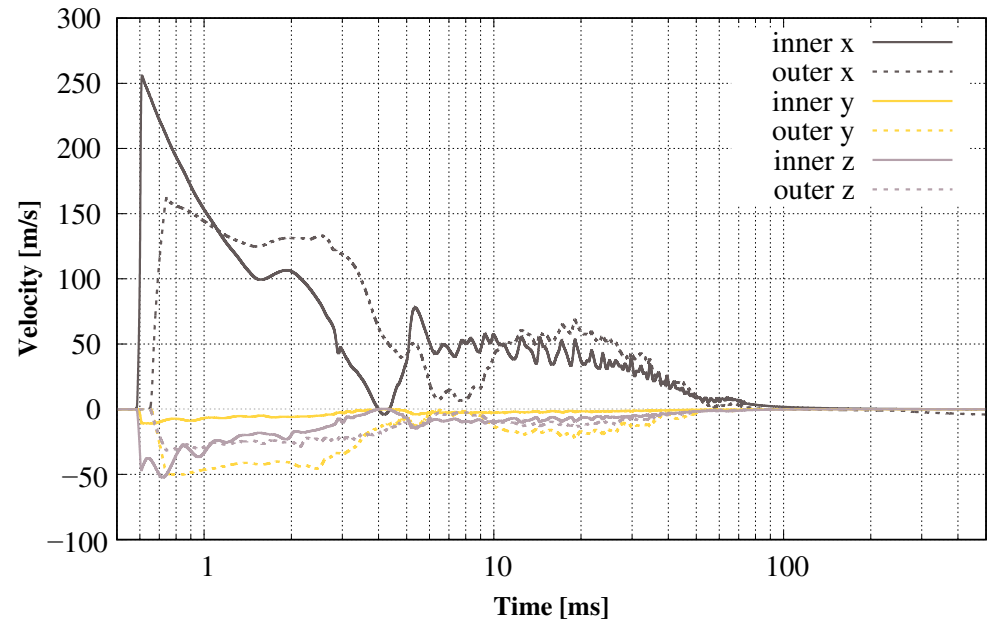

Figure 9. Velocity distribution along axes and channels. 
The amount of air mass is also important regarding energy distribution. The quantity of mass and the quantity of motion are related to density. The analysis of flow phenomena for compressible flows is not complete if the mass flux and its dependence on velocity are not considered. The change in mass flux with a corresponding change in velocity is shown in Figure 10.

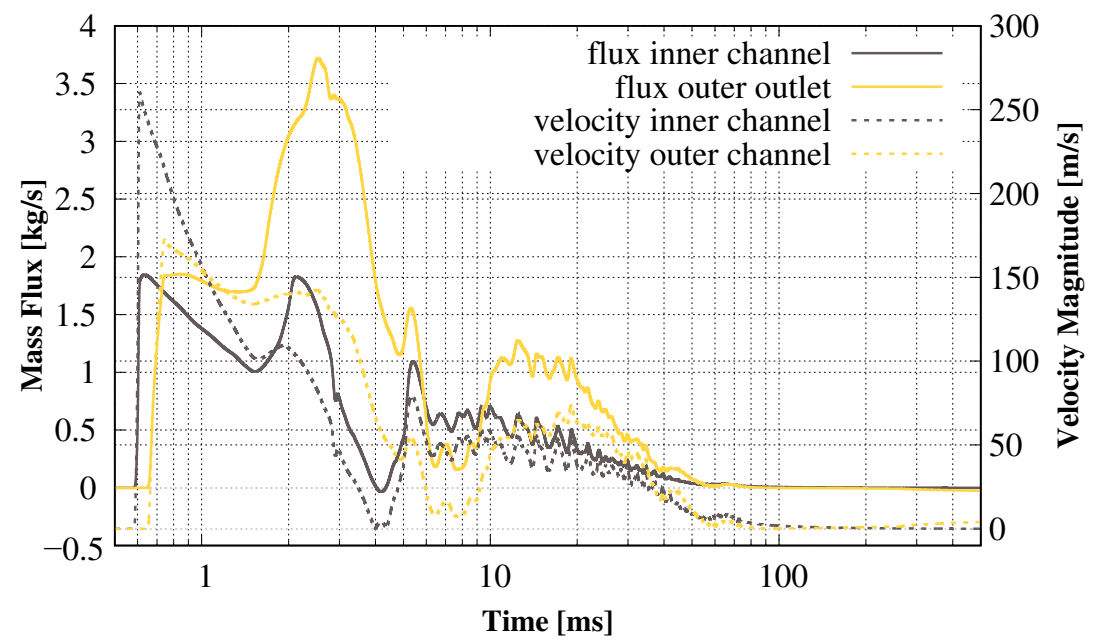

Figure 10. Mass flux and velocity magnitude distribution between considered outlet channels.

This graph shows the average discharge velocity for each channel and the mass flow rate. The velocity change is not always accompanied by a corresponding change in mass flow rate. This can be seen for both outlet channels for times between $1.5 \mathrm{~ms}$ and $4 \mathrm{~ms}$. Despite the rapid decrease in velocity, there is a significant increase in the outlet mass flux value. This response occurs only when there is a significant change in density, which clearly indicates strong gas compression and outlet choking. This period coincides with the air reaching the highest Mach number value as shown in Figure 11. At the same time, it is also noteworthy that the averaged Mach number value is also non-uniformly distributed among the channels (Figures 11 and 12).

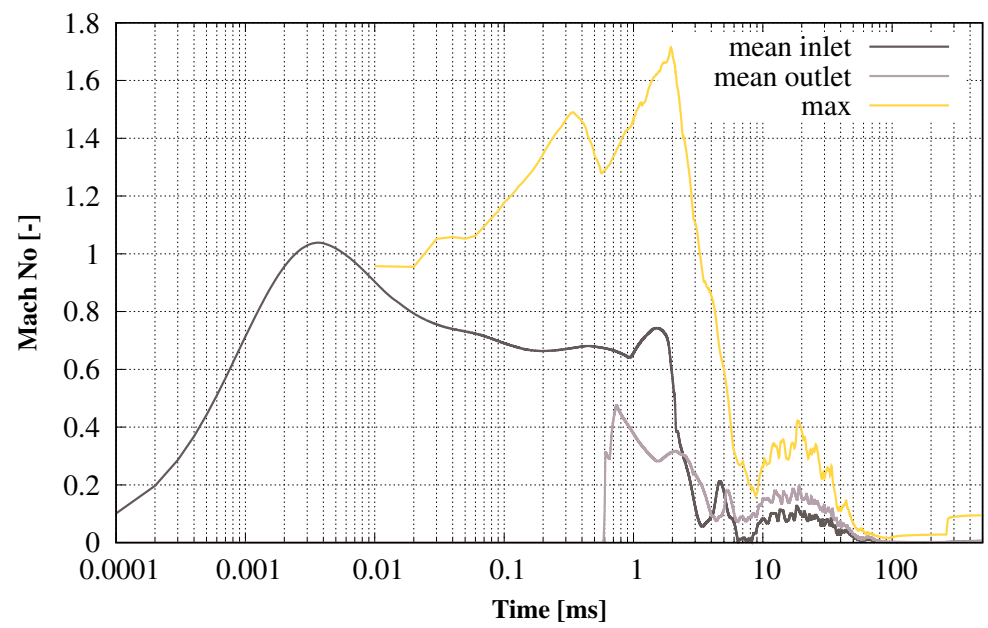

Figure 11. Mean and maximal Mach number at inlet and outlet of the nozzle. 


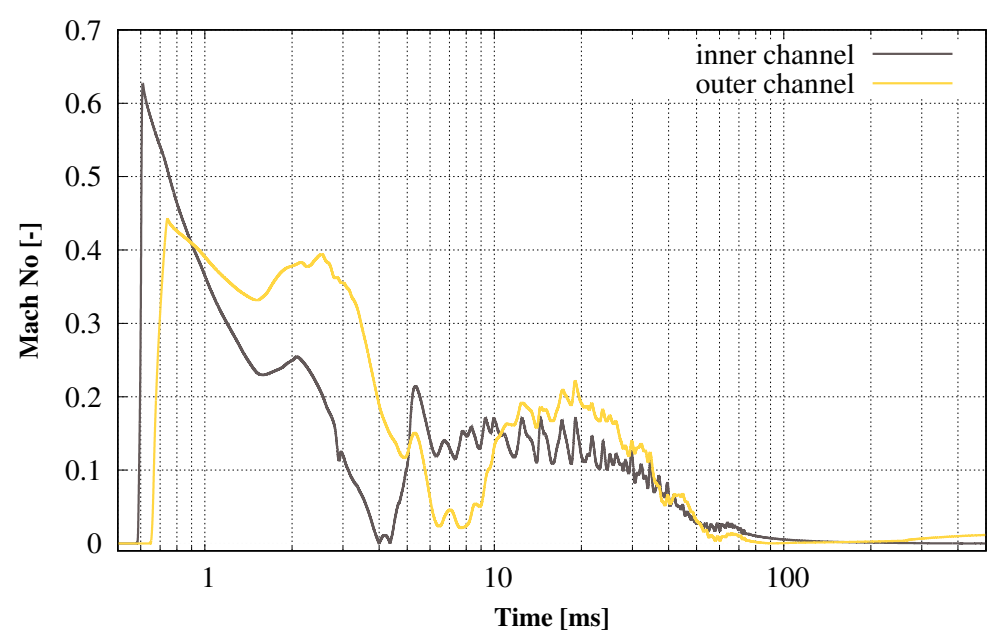

Figure 12. Mach number distribution at the outlet channels.

Pressure and temperature are also important parameters for flow and energy analyses. The time distributions of the inlet values are shown in Figure 13. These values are absolute. At the beginning of the process, the highest inlet pressure value is $0.6 \mathrm{MPa}$. This value results directly from the imposed boundary conditions. Similarly, the same graph shows the inlet temperature with the highest value of $300 \mathrm{~K}$. After a steep decrease at the beginning of the process, the inlet pressure and temperature increase between $1 \mathrm{~ms}$ and $3 \mathrm{~ms}$. The increase in these parameters is gas compression due to choked outflow. This can be seen in the graph in Figure 14, exceptionally dynamic in the inner channel. An additional influence on the inlet parameters could be the existence of a baffle causing compression at the very beginning of the process.

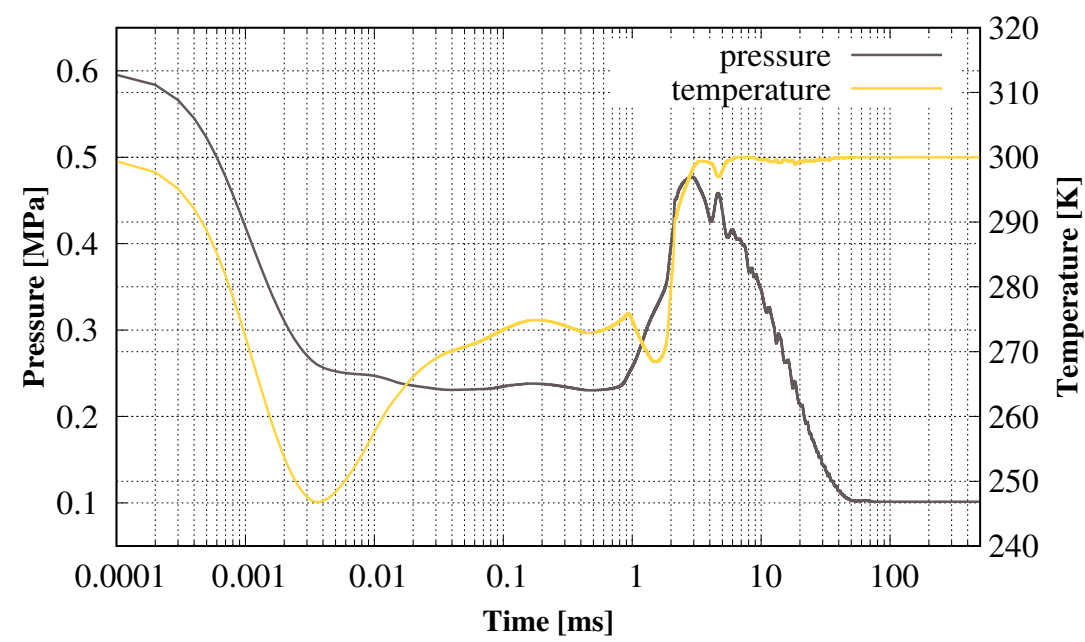

Figure 13. Inlet pressure and temperature time distribution.

It is also noteworthy that the outlet pressure for the inner channel increases above the initial value and exceeds $0.7 \mathrm{MPa}$. Such a strong gas compression will affect the energy and exergy of the outlet gas from the nozzle. Thus, it will strongly influence the energy transfer to the loose material.

The strong compression is also followed by rapid decompression of the gas. This results in a temperature drop of about $240 \mathrm{~K}$, which is 60 degrees below the initial value. The temperature drop below the initial value did not result in a vacuum in the nozzle. The range of temperature change is very significant and is as high as $268 \mathrm{~K}$. Interestingly, such gas cooling is observed only in the inner channel. The range of temperature change in 
the outer channel is almost twice smaller and is $137 \mathrm{~K}$. There are differences in the spectrum of thermodynamic conversions between the channels.

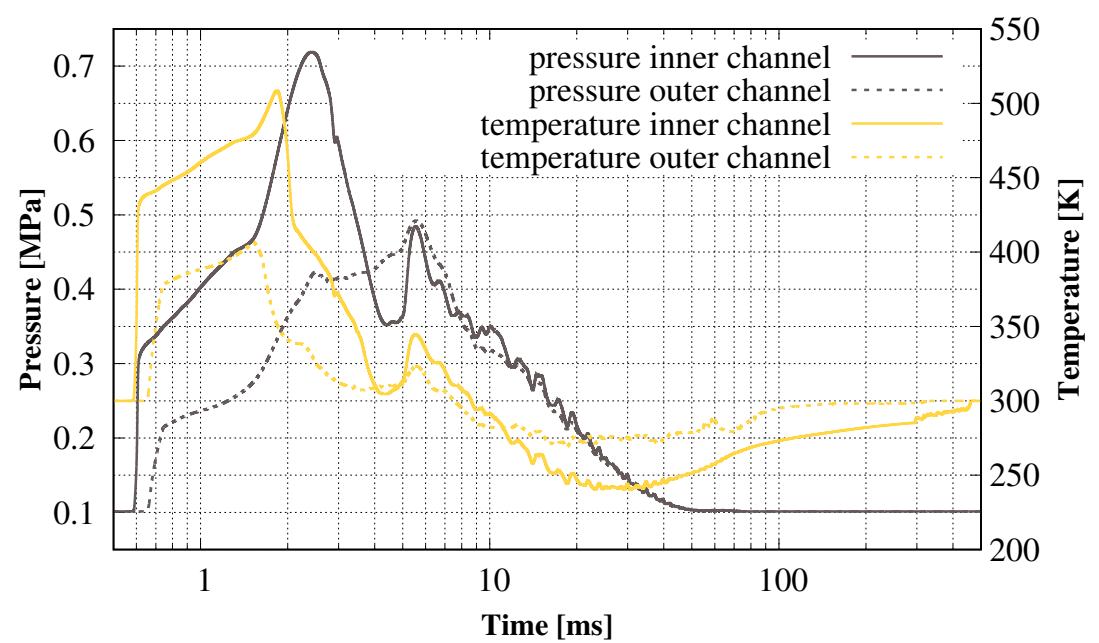

Figure 14. Outlet pressure and temperature time distribution.

The aforementioned phenomena arising from changes in inlet and outlet parameters are confirmed by the contour plots given in Figures 15 and 16 as well as in Figure 17. Due to a large amount of data, only a portion of them is presented. The bottom part of the computational area is shown as a continuous point cloud. The upper part of the computational area shows contours for selected ten values from the entire spectrum of results for given parameters (i.e., pressure, temperature, Mach number). Both types of graphs are coloured according to the same scale shown below the snapshots. Only the most characteristic time moments have been selected.

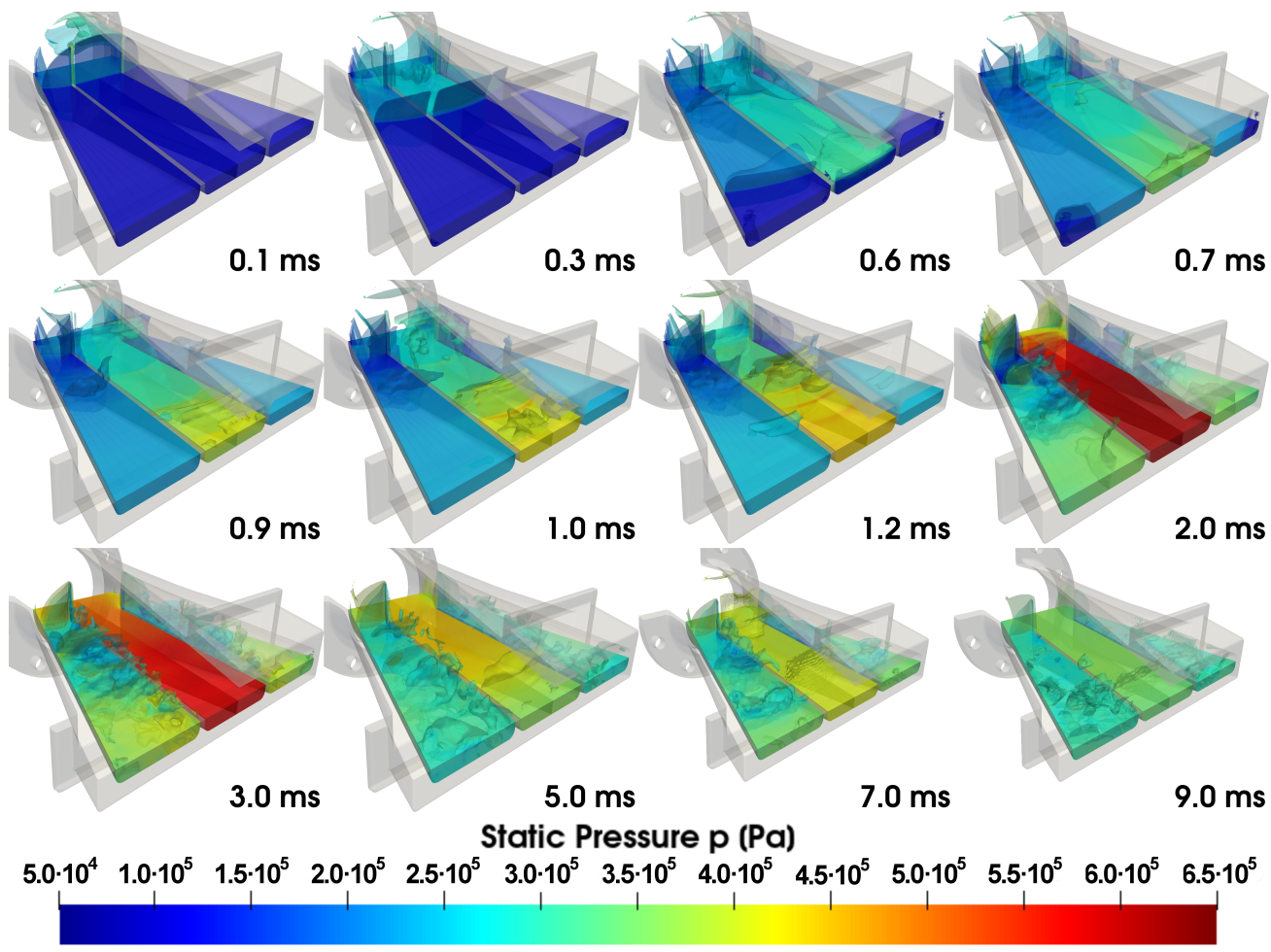

Figure 15. Snapshots of pressure contour plots for 12 time frames. 
In the inner channel, the air reaches the outlet area faster. There is also very strong compression along the entire length of the channel. The shape of the inner channel is more nearly rectangular in longitudinal section than the outer channels. The outer channels widen towards the outlet, which causes the air to expand more easily. Therefore, it acts as a diffuser. This design results in less compression, which gives a more uniform outflow of gas from the outer channels over time. It can be observed in the Figure 17 that shows the Mach number.

Strong compression can also be seen in the contour plots representing temperature in Figure 16. As the pressure increases, the temperature also increases, reaching values above $500 \mathrm{~K}$ (i.e., $235^{\circ} \mathrm{C}$ ). The expanding outer channel acts as a diffuser, causing the temperature to drop over time, which is confirmed by pressure results. The strong compression in the inner channel as the temperature increases can be crucial in the amount of energy transferred to the loose material. At the same time, a more stable flow in the outer channel over time can result in more efficient energy transfer.

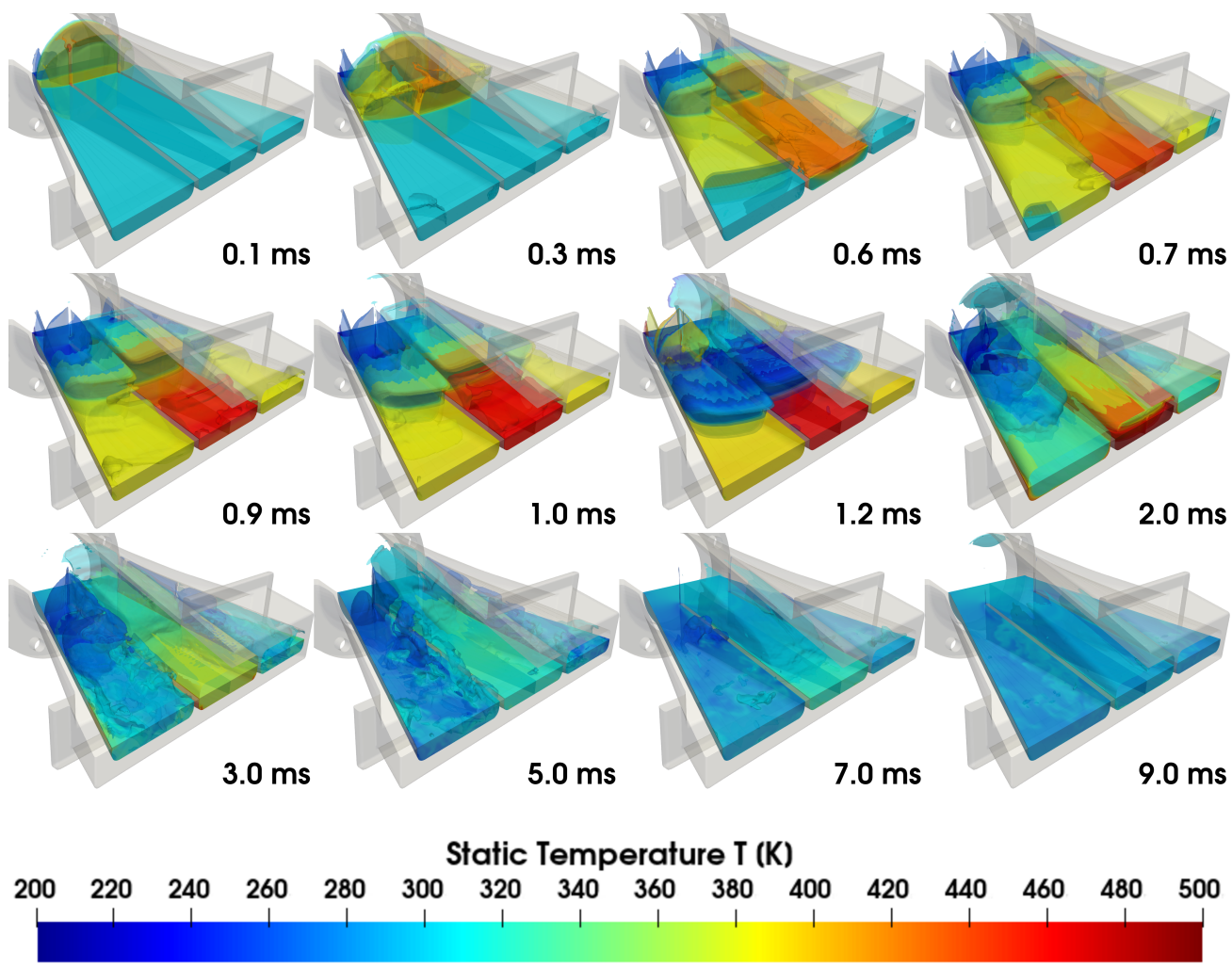

Figure 16. Snapshots of temperature contour plots for 12 time frames.

It is convenient to use criterion numbers to illustrate the nature of flow phenomena more fully. The key dimensionless number for compressible flows is the Mach number. By definition, it is the ratio of the gas velocity to the speed of sound at a given pressure. It is convenient to use an extended equation including the pressure and density of the gas, as presented below:

$$
M a=\frac{|\vec{u}|}{\sqrt{\gamma p / \rho}}
$$

The distribution of Mach number can be represented by contour plots similarly to pressure and temperature ones. It is shown as snapshots in Figure 17. Mach number associates velocity, pressure and density. The lower Mach number values can be seen in the inner channel, confirming the choked flow occurrence. The highest Mach number for the inlet is 1.04. The highest for the outlet in the inner channel is 0.63 , while the highest in the outer channel is 0.44 . The highest Mach number for the entire considered area is 
1.73. Such a high increase in temperature and pressure and a decrease in Mach number confirm the choked flow in the inner channel. It has been shown in the appropriate Figures of pressure (Figure 15) and temperature (Figure 16). Additionally, the changes do not occur as dynamically in the outer channels. It is confirmed by the Mach number outlet values shown in the graph in Figure 12.

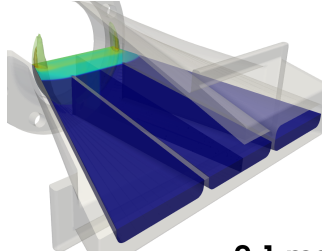

$0.1 \mathrm{~ms}$

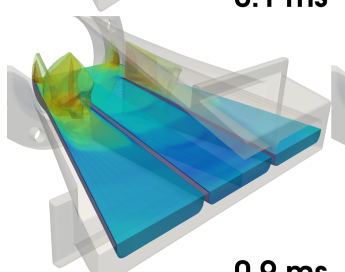

$0.9 \mathrm{~ms}$

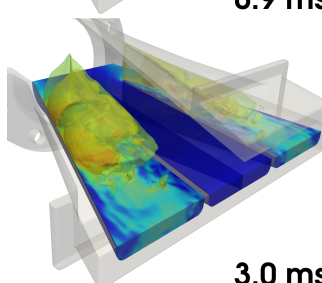

$3.0 \mathrm{~ms}$

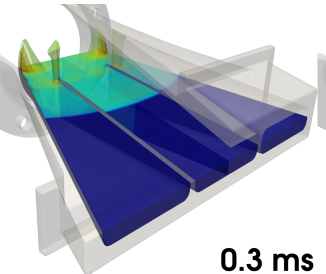

$0.3 \mathrm{~ms}$

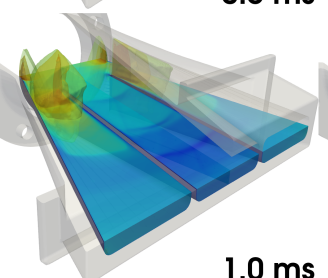

$1.0 \mathrm{~ms}$

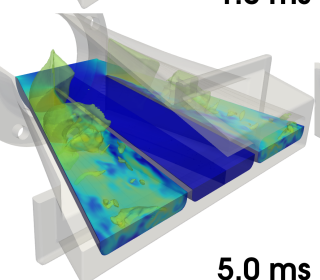

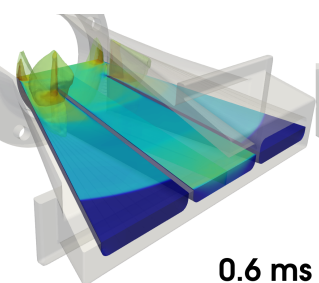

$0.6 \mathrm{~ms}$

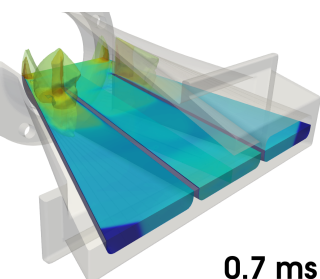

$0.7 \mathrm{~ms}$

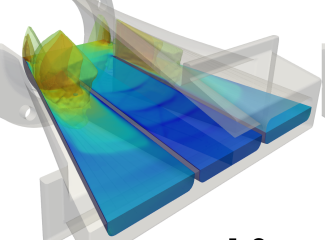

$1.2 \mathrm{~ms}$

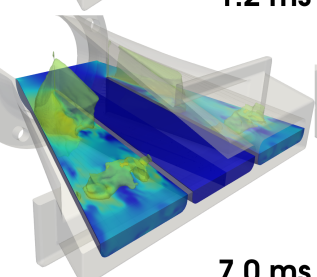

$7.0 \mathrm{~ms}$

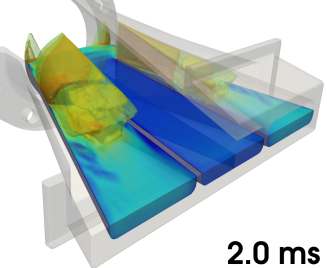

$2.0 \mathrm{~ms}$

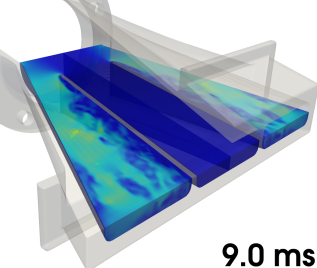

Mach Number Ma (-)

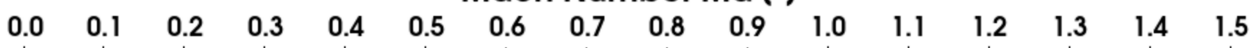

Figure 17. Snapshots of Mach number contour plots for 12 time frames.

\subsection{Energy Analysis Results}

The amount of energy and exergy transferred through the nozzle is the result of a flow parameters combination, which follows directly from the Equations (20) and (23). However, not every parameter has an identical influence. The graphs shown in Figure 18 illustrates the change in energy over time. These values are averaged for inlet and outlet without distinguishing the outlet channels.

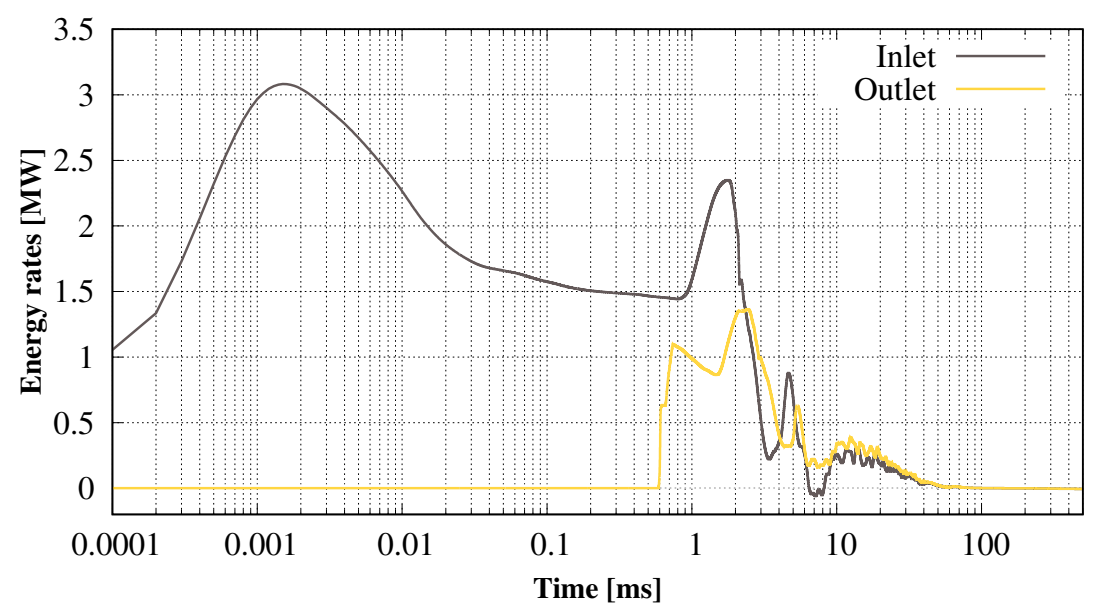

Figure 18. Inlet and outlet energy time distribution. 
The most significant influence on the energy value is velocity. This is due to the kinematic energy relationship, in which velocity is squared. An additional effect of velocity is due to the vector field of the mass flux, in which velocity is related to the density of the gas. The negligible impact of pressure on energy can be seen. Figure 19 shows plots of the change in energy flux and exergy over time, taking into account the distribution of these between channels.

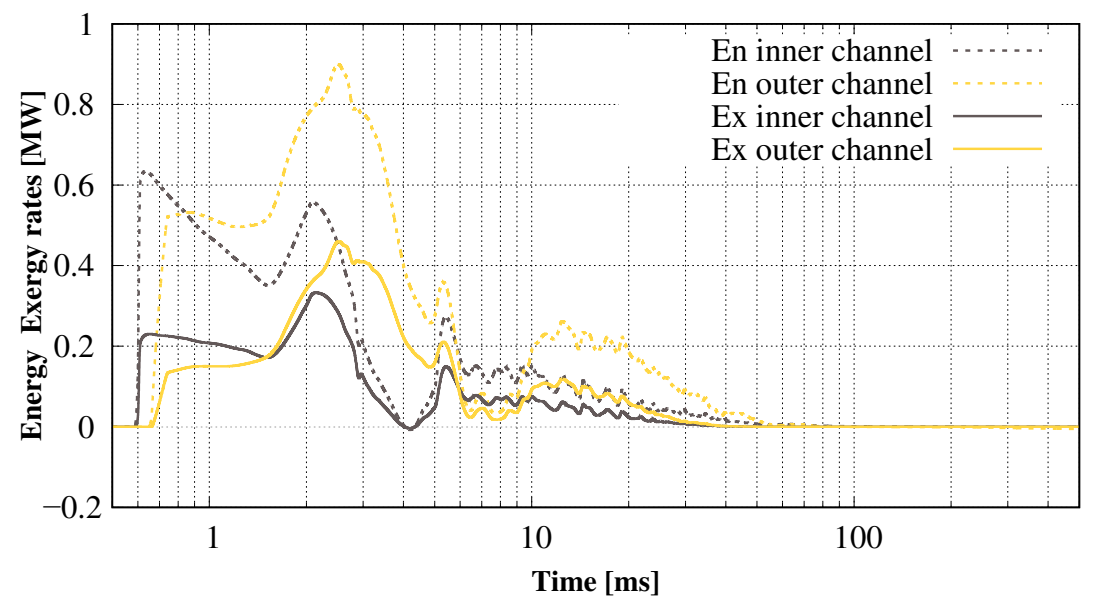

Figure 19. Outlet energy and exergy according to channel.

It is worth noticing that much lower energy and exergy values occur for the inner channel. The relationship Equation (23) indicates a significant effect of temperature and pressure on the exergy value. This would mean that an increase in these parameters should increase the exergy of the gas. However, this is not observed.

The energy analysis concludes by determining the energy and exergy values throughout the process. Time derivatives of energy and exergy gave energy and exergy rates. Thus, the rates needed to be integrated over time to calculate total energy and exergy at inlets and outlets. Since numerical simulation gives discretised results, the integral can be converted into sums as follows:

$$
\begin{gathered}
E=\int \dot{E} \mathrm{~d} t=\sum \dot{E} \Delta t \\
E x=\int \dot{E} x \mathrm{~d} t=\sum \dot{E} x \Delta t
\end{gathered}
$$

where $\Delta t$ is time step. The time step was not synonymous with a time step of numerical simulation. In the present study, the time step used in Equations (25) and (26) has been set to $10^{-5} \mathrm{~s}$, and it was the time step of the numerical data writing.

After this operation, the values of energy and exergy could be determined for inlets and outlets. These values could be compared to determine the energy loss and exergy destruction. The results of energy and exergy at inlets and outlets are presented in Table 1 below:

Table 1. Results of energy efficiency analysis. "\%" mean percentage of inlet energy.

\begin{tabular}{lccclcll}
\hline & Inlet & Outlet & $\%$ & $\begin{array}{l}\text { Inner } \\
\text { Channel }\end{array}$ & $\%$ & $\begin{array}{l}\text { Outer } \\
\text { Channel }\end{array}$ & $\%$ \\
\hline Energy [J] & $10,399.0$ & $10,322.1$ & $99.26 \%$ & 3928.8 & $37.37 \%$ & 6393.3 & $61.48 \%$ \\
Exergy [J] & - & 4395.0 & $42.26 \%$ & 1621.1 & $15.59 \%$ & 2773.9 & $26.67 \%$ \\
\hline
\end{tabular}

The difference between the inlet and outlet energy values is noticeable in the table above. Energy cannot be created or destroyed, and the nozzle walls are impermeable. The difference is $0.74 \%$ of the inlet energy value. This value should be considered as averaging error because the numerical simulation results are averaged in spatial and 
temporal terms. Therefore, the calculation error values shown in Section 2.4 overlap with the averaging errors in time and space.

Inlet exergy value had to be omitted in studies of nozzles efficiency because of its unphysical meaning. If the value of inlet exergy is given, work is done in the nozzle, which is obviously impossible in the presented case. The investigated problem considers the amount of energy that could be transferred onto work inside silos for energy efficiency; therefore, the most important is the exergy value at the outlet.

The total exergy at the outlet relative to the energy at the inlet is $42.26 \%$. It means that more than half of the nozzle inlet energy cannot be converted into work. Let us take into account the distribution of exergy into individual channels. Exergy allocated to the inner channel is $15.59 \%$ of inlet energy, while that allocated to outer channels is $26.67 \%$ of inlet energy. It shows that the outer channels transfer energy much more efficiently than the inner channel.

\subsection{Exergy at Different Ambient Conditions}

Exergy depends on ambient temperature what strictly arises from Equation (23). Determination of ambient conditions is a task of the analyst, and it depends on a considered system balance shield. The ambient conditions are environmental ones in most cases. In the considered cases, the nozzle outlet conditions can change, and they could be apart from the environmental parameters. Therefore, it is appropriate to analyse how exergy values are affected by changing the inner silo parameters. The gas parameters that could be taken into account are pressure and temperature. Most silos in the industry are open (pressureless), so choosing temperature changes was decided for exergy analysis.

Exergy and energy analysis was carried out by assuming a constant environmental value of the ambient temperature of $300 \mathrm{~K}$. So the values of outlet exergy were recalculated with an ambient temperature between $250 \mathrm{~K}$ and $450 \mathrm{~K}$. The results are shown in Figure 20.

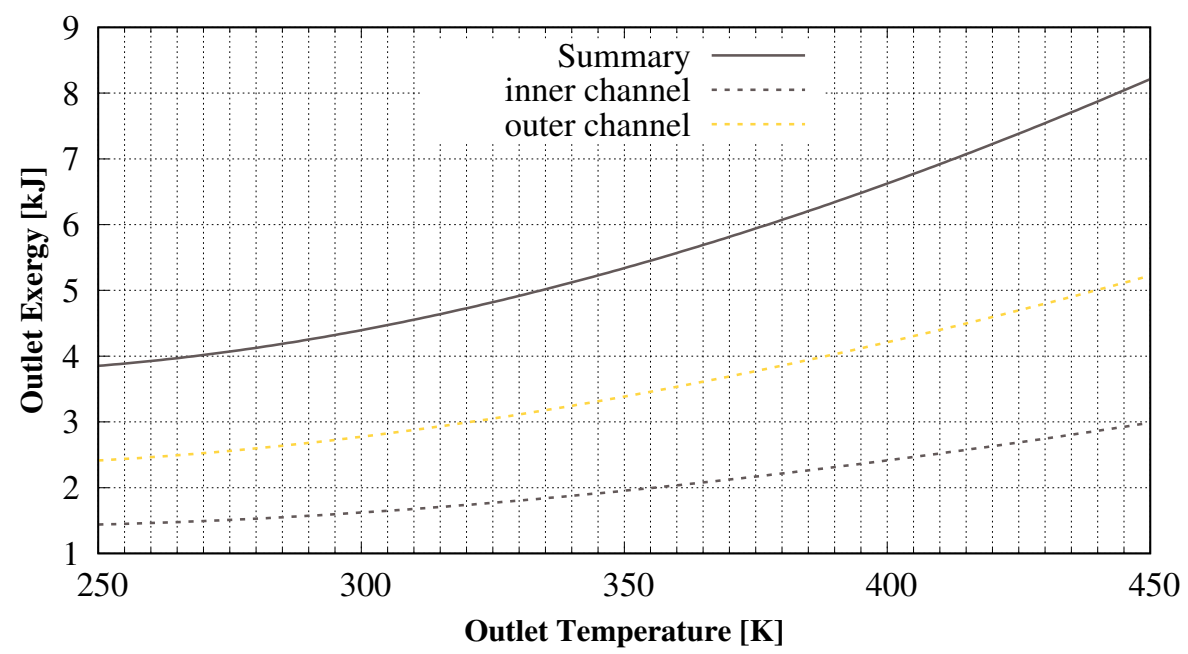

Figure 20. Outlet pressure and temperature time distribution.

The graph of a function is exponential, as can be noticed. It strictly arises from Equation (23). The value of exergy increase with temperature. The temperature range was arbitrarily chosen for values that can be met in actual industrial conditions. There is a substantial increase in exergy with temperature. The difference is $0.99 \mathrm{~kJ}$ for the lowest considered temperature of $250 \mathrm{~K}$ and $2.21 \mathrm{~kJ}$ for the highest temperature of $450 \mathrm{~K}$. Regarding the inlet energy for a reference temperature of $300 \mathrm{~K}$, the amount of energy that can be converted into work is, respectively: $37.05 \%$ and $78.98 \%$. 


\section{Concluding Remarks}

The author focused on developing a method and performing a detailed energy analysis of an industrial nozzle in the presented article. A comprehensive analysis can be extensive. This article presents a small part of the energy analysis of a nozzle. The scope of this analysis was motivated by the assumptions made. First of all, the influence of thermodynamic gas conversions on the nozzle efficiency is of major importance. These aspects were crucial in the presented research. The nozzle that distributes the energy flux is not an efficient device. Exergy losses add up to more than 50\%. In addition, the uneven distribution of the energy flux across all channels is a disadvantage. Despite the similar cross-sectional area of both outlet channels, the inner channel delivers significantly less energy and exergy rates than the outer channels. The increase in pressure and temperature in the inner channel does not translate into the amount of energy transferred to the loose material. The substantial compression of the gas in the inner channel relative to the outer channel generates much less energy and causes a significant decrease in exergy. Every thermodynamic conversion causes an increase in entropy. It shows how rapid thermodynamic conversions contribute to energy losses due to increasing entropy. When gas flows during the working cycle, fluctuations and energy peaks occur due to the same behaviour of flow parameters such as velocity, pressure and temperature. Thus, the effectiveness of the nozzle to purge unfavourable structures in loose materials is not high.

An analysis has also been carried out to provide technical assumptions to guide the operation process. An idealised assumption was made about the possibility of changing the temperature in the silo, which in the exergetic analysis would mean changing the ambient temperature. From this analysis, it can be concluded that it is necessary to keep the temperature in the silo as high as possible in order to increase the nozzle efficiency. Whether this is even possible for technological reasons remains an open question.

The general conclusion could be a need for design changes resulting from inefficient energy use. The investigated nozzle is an operative but the inefficient industrial object. However, many questions and doubts have arisen about the purpose of the baffle. The relevance of its usage should be resolved in further work. Although, one might be tempted to state that a smoother change of the inlet pressure would be advisable. Starting the process too dynamically does not allow the air energy to be used efficiently. It is similar to an engine knocking in an internal combustion engines. The choked flow in the inner channel is of great importance for energy efficiency. This phenomenon is disadvantageous in this aspect, and a diffuser-shaped design should be considered, as is the case with outer channels.

Funding: This research received no external funding.

Institutional Review Board Statement: Not applicable.

Informed Consent Statement: Not applicable.

Data Availability Statement: Not applicable.

Conflicts of Interest: The author declares no conflict of interest.

\section{Abbreviations}

The following abbreviations are used in this manuscript:

$\begin{array}{ll}\text { CFD } & \text { Computational Fluid Dynamics } \\ \text { FVM } & \text { Finite Volume Method } \\ \text { FEM } & \text { Finite Element Method } \\ \text { LES } & \text { Large Eddy Simulation } \\ \text { RANS } & \text { Reynolds Averaged Navier-Stokes } \\ \text { GCI } & \text { Grid Convergence Index } \\ \text { CFL } & \text { Courant-Friedrichs-Levy convergence criterion }\end{array}$




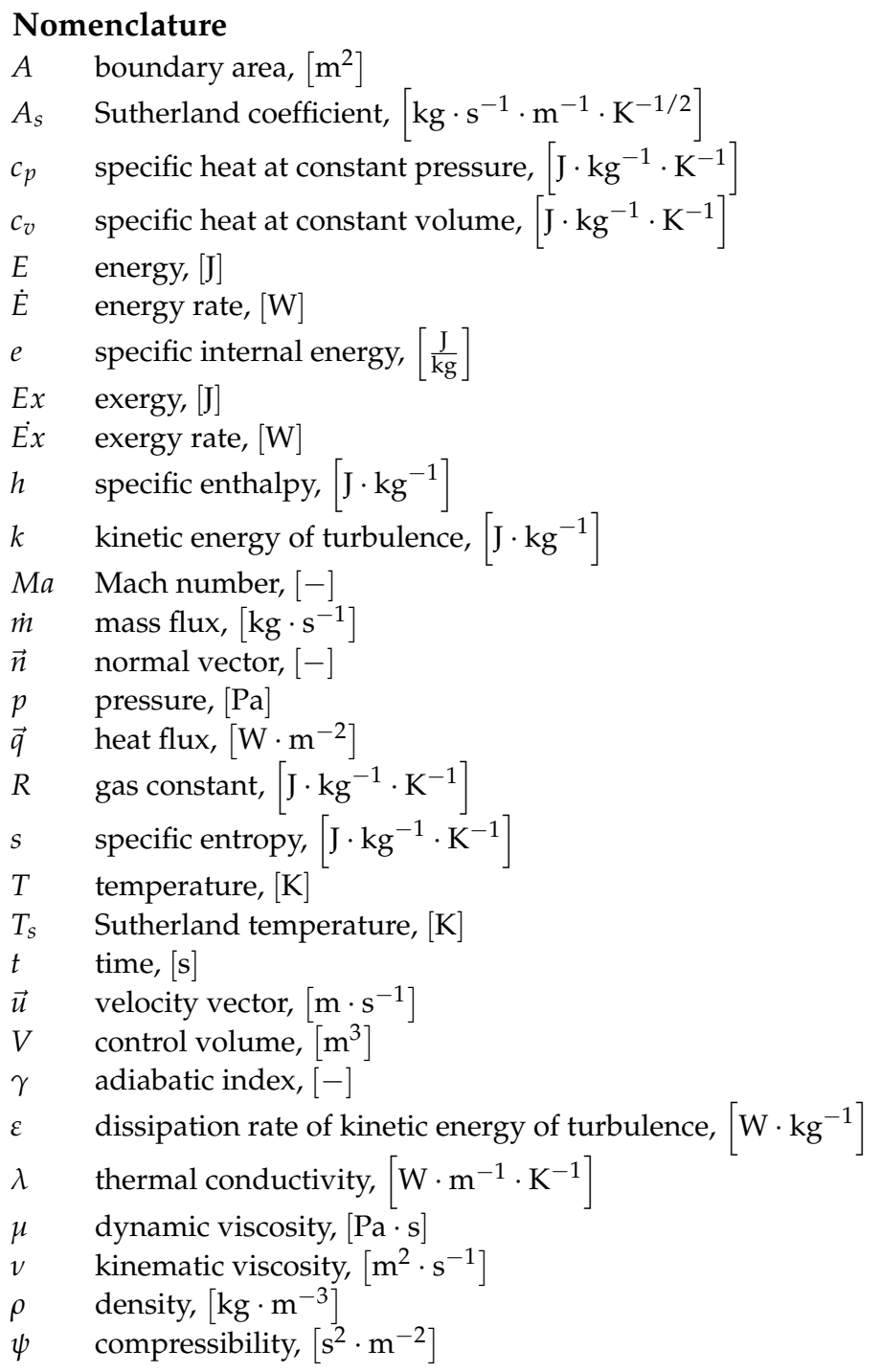

\section{References}

1. Staruszkiewicz, A. Krótka historia pojęcia energii. Foton 2011, 114, 4-8. (In Polish)

2. Wegener, F.D.A. A True Proteus: A History of Energy Conservation in German Science and Culture, 1847-1914. Ph.D. Thesis, Universiteit Utrecht, Utrecht, The Netherlands, 2009.

3. Dincer, I.; Rosen, M.A. Exergy: Energy, Environment and Sustainable Development; Newnes: London, UK, $2012 ;$ p. 571.

4. Szargut, J. Exergy Method: Technical and Ecological Applications; WIT Press: Southampton, UK, 2005; p. 189.

5. Alekseev, G.N. Energy and Entropy; Mir Publishers: Moscow, Russia, 1986; p. 200.

6. Yang, Y.; Zhu, X.; Yan, Y.; Ding, H.; Wen, C. Performance of supersonic steam ejectors considering the nonequilibrium condensation phenomenon for efficient energy utilisation. Appl. Energy 2019, 242, 157-167. [CrossRef]

7. Schmandt, B.; Herwig, H. Diffuser and Nozzle Design Optimization by Entropy Generation Minimization. Entropy 2011, 13, 1380-1402. [CrossRef]

8. Kirmaci, V.; Kaya, H.; Cebeci, I. An experimental and exergy analysis of a thermal performance of a counter flow Ranque-Hilsch vortex tube with different nozzle materials. Int. J. Refrig. 2018, 85, 240-254. [CrossRef]

9. Adhikari, R.C.; Wood, D.H. A new nozzle design methodology for high efficiency crossflow hydro turbines. Energy Sustain. Dev. 2017, 41, 139-148. [CrossRef]

10. Weilenmann, M.; Noiray, N. Experiments on sound reflection and production by choked nozzle flows subject to acoustic and entropy waves. J. Sound Vib. 2021, 492, 115799. [CrossRef]

11. Ishak, M.H.; Ismail, F.; Mat, S.C.; Abdullah, M.Z.; Abdul Aziz, M.S.; Idroas, M.Y. Numerical Analysis of Nozzle Flow and Spray Characteristics from Different Nozzles Using Diesel and Biofuel Blends. Energies 2019, 12, 281. [CrossRef]

12. Hemidi, A.; Henry, F.; Leclaire, S.; Seynhaeve, J.M.; Bartosiewicz, Y. CFD analysis of a supersonic air ejector. Part II: Relation between global operation and local flow features. Appl. Therm. Eng. 2009, 29, 2990-2998. [CrossRef] 
13. Huet, M.; Emmanuelli, A.; Ducruix, S. Influence of viscosity on entropy noise generation through a nozzle. J. Sound Vib. 2021, 510, 116293. [CrossRef]

14. Quaatz, J.F.; Giglmaier, M.; Hickel, S.; Adams, N.A. Large-eddy simulation of a pseudo-shock system in a Laval nozzle. Int. J. Heat Fluid Flow 2014, 49, 108-115. [CrossRef]

15. Ota, M.; Udagawa, S.; Inage, T.; Maeno, K. Interferometric Measurement in Shock Tube Experiments. In Interferometry-Research and Applications in Science and Technology; Padron, I., Ed.; InTech: New York, NY, USA, 2012; Chapter 11, pp. $226-244$.

16. Inage, T.; Tsuchikura, S.; Ota, M.; Maeno, K. Three-dimensional laser interferometric CT (LICT) measurement of shock wave interaction around a circular cylinder. Flow Meas. Instrum. 2013, 31, 102-106. [CrossRef]

17. Honma, H.; Ishihara, M.; Yoshimura, T.; Maeno, K.; Morioka, T. Interferometric CT measurement of three-dimensional flow phenomena on shock waves and vortices. Shock Waves 2003, 13, 179-190. [CrossRef]

18. Bergersen, A.W.; Mortensen, M.; Valen-Sendstad, K. The FDA nozzle benchmark: "In theory there is no difference between theory and practice, but in practice there is". Int. J. Numer. Methods Biomed. Eng. 2019, 35, e3150. [CrossRef] [PubMed]

19. Szargut, J. Egzergia: Poradnik Obliczania i Stosowania [in Polish]; Wydawnictwo Politechniki Ślasskiej: Gliwice, Poland, $2007 ;$ p. 129.

20. Bejan, A. Entropy Generation Through Heat and Fluid Flow; Wiley: Hoboken, NJ, USA, 1982; p. 248.

21. Hassan, H.Z. Evaluation of the local exergy destruction in the intake and fan of a turbofan engine. Energy 2013, 63, 245-251. [CrossRef]

22. Kröner, D.; LeFloch, P.G.; Thanh, M.D. The minimum entropy principle for compressible fluid flows in a nozzle with discontinuous cross-section. ESAIM Math. Model. Numer. Anal. 2008, 42, 425-442. [CrossRef]

23. Rohrbach, Z.J.; Buresh, T.R.; Madsen, M.J. Modeling the exit velocity of a compressed air cannon. Am. J. Phys. 2012, 80, 24-26. [CrossRef]

24. Wołosz, K.J. Exergy destruction in the pneumatic pulsator system during one working cycle. Energy 2018, 146, 124-130. [CrossRef]

25. Wołosz, K.J.; Wernik, J. Heat generation calculation on the basis of numerical simulation results of supersonic airflow in a nozzle. Chem. Eng. Trans. 2014, 39, 1363-1368. [CrossRef]

26. Wołosz, K.J.; Wernik, J. On the heat in the nozzle of the industrial pneumatic pulsator. Acta Mech. 2016, 227, 1111-1122. [CrossRef]

27. Weller, H.G.; Tabor, G.; Jasak, H.; Fureby, C. A tensorial approach to computational continuum mechanics using object-oriented techniques. Comput. Phys. 1998, 12, 620. [CrossRef]

28. Petrila, T.; Trif, D. Basics of Fluid Mechanics and Introduction to Computational Fluid Dynamics; Springer: Boston, MA, USA, 2005.

29. Pozrikidis, C. Fluid Dynamics: Theory, Computation, and Numerical Simulation; Springer: Boston, MA, USA, 2009.

30. Menter, F.R. Two-equation eddy-viscosity turbulence models for engineering applications. AIAA J. 1994, 32, 1598-1605. [CrossRef]

31. Tu, J.; Yeoh, G.H.; Liu, C. Computational Fluid Dynamics. A Practical Approach; Elsevier: Amsterdam, The Netherlands, 2008.

32. Wołosz, K.J.; Wernik, J. Comparative Study on Heat Generation During Compressible Airflow Through Heatproof Nozzles. Chem. Eng. Trans. 2018, 70, 151-156. [CrossRef]

33. Utyuzhnikov, S. Robin-type wall functions and their numerical implementation. Appl. Numer. Math. 2008, 58, 1521-1533. [CrossRef]

34. Giglmaier, M.; Quaatz, J.F.; Gawehn, T.; Gülhan, A.; Adams, N.A. Numerical and experimental investigations of pseudo-shock systems in a planar nozzle: Impact of bypass mass flow due to narrow gaps. Shock Waves 2014, 24, 139-156. [CrossRef]

35. Courant, R.; Friedrichs, K.; Lewy, H. Über die partiellen Differenzengleichungen der mathematischen Physik. Math. Ann. 1928, 100, 32-74. [CrossRef]

36. Freitas, C.J. The issue of numerical uncertainty. Appl. Math. Model. 2002, 26, 237-248. [CrossRef]

37. Ferziger, J.H.; Perić, M. Computational Methods for Fluid Dynamics; Springer: Berlin, Germany, 2002.

38. Szumowski, A.; Selerowicz, W.; Piechna, J. Dynamika Gazów; Wydawnictwa Politechniki Warszawskiej: Warszawa, Poland, 1988. (In Polish)

39. Costa, V.A.F. On the exergy balance equation and the exergy destruction. Energy 2016, 116, 824-835. [CrossRef]

40. Bejan, A. Fundamentals of exergy analysis, entropy generation minimization, and the generation of flow architecture. Int. J. Energy Res. 2002, 26, 545-565. [CrossRef]

41. Szargut, J.; Ziębik, A. Podstawy Energetyki Cieplnej; PWN: Warszawa, Poland, 1998. (In Polish) 